\title{
Central Nervous System Sarcoma
}

National Cancer Institute

\section{Source}

National Cancer Institute. Central Nervous System Sarcoma. NCI Thesaurus. Code C5153.

A sarcoma that arises from the central nervous system. 